\title{
LEVANTAMENTO DA ÁREA IRRIGADA POR PIVÔ CENTRAL NA MICRORREGIÃO NOROESTE I DO ESTADO DO ESPÍRITO SANTO
}

\author{
Rebyson Bissaco Guidinelle ${ }^{1}$ \\ Israel Martins Pereira ${ }^{2}$ \\ Alex Justino Zacarias ${ }^{3}$ \\ Otavio Delaqueza Arruda Ferro ${ }^{4}$ \\ Jéferson Luiz Ferrari ${ }^{5}$
}

Resumo: Este trabalho teve como objetivo realizar o levantamento da área irrigada por pivô central na Microrregião Noroeste I, estado do Espírito Santo, Brasil. O levantamento da área irrigada por pivô central foi realizado mediante o uso do programa Google Earth ${ }^{T M}$ Pro. Foi feito a sobreposição do arquivo vetorial da microrregião sobre a imagem de satélite disponível no programa computacional. Em seguida foi realizada a fotointerpretação de todas as áreas irrigadas com pivô central. A escala utilizada foi de 1:1.000. Foram levantados o raio $(\mathrm{m})$, o perímetro $(\mathrm{m})$ e a área do alvo fotointerpretado. Chegando à uma conclusão que a microrregião possui apenas uma área irrigadas por pivô central, totalizando 36,33 há irrigado por esse sistema.

Palavras-chave: Geoprocessamento; Google EarthTM Pro; Fotointerpretação; Mapa de uso da terra.

\footnotetext{
1 Graduando em Tecnologia em Cafeicultura/Instituto Federal do Espírito Santo, Campus de Alegre, IFES - ES, Brasil. E-mail: rebysonguidinelle@gmail.com.

2 Graduando em Tecnologia em Cafeicultura/Instituto Federal do Espírito Santo, Campus de Alegre, IFES - ES, Brasil. E-mail: israelmartins80@gmail.com.

${ }^{3}$ Graduando em Tecnologia em Cafeicultura/Instituto Federal do Espírito Santo, Campus de Alegre, IFES - ES, Brasil. E-mail: alexjustino12@gmail.com.

${ }^{4}$ Graduando em Tecnologia em Cafeicultura/Instituto Federal do Espírito Santo, Campus de Alegre, IFES - ES, Brasil. E-mail: otaviodelaka@gmail.com.

5 Professor/Instituto Federal do Espírito Santo, Campus de Alegre, IFES - ES, Brasil. E-mail: ferrarijluiz@gmail.com.
} 